[Aus dem hygienischen Institut der Universität Berlin.]

\title{
Ueber das Wachsthum des Rauschbrandbacillus in festen Nährsubstraten.
}

Nachtrag zu der Abhandlang: „Ueber den Rauschbrandbacillus and sein Culturverfahren.“ 1

$$
\text { Von }
$$

Dr. med. S. Kitasato

aus Tokio.

(Hierza Taf. III.)

Wie ich in meiner früheren Publication über den Rauschbrandbacillus mitgetheilt habe, konnte ich denselben bis dahin noch nicht in festen Nährböden cultiviren. Es ist mir jetzt gelungen, diese Aufgabe zu lösen.

Ein Meerschweinchen wurde mit einer Bouilloncultur von Rauschbrandbacillen geimpft und ging nach 30 Stunden daran zu Grunde. Es wurde etwas von der bacillenhaltigen blutig-serösen Flüssigkeit in platte Glasgefässe mit neutralem Agar-Nährboden gebracht, gemischt und einem Strom von Wasserstoffgas ausgesetzt. Nach Verschluss dieser Gefässe wuchsen im Brütschrank nach 24 Stunden Colonieen, welche unregelmässige Kugeln mit leicht warziger Oberfläche bildeten. Nach Aufbrechen des Gefässes wurden vermittelst einer Platinnadel von einer derartigen Colonie in frischem Agar in hoher Schicht Stichculturen angelegt. Mikroskopisch erwiesen sich die Bacterien als kurze Stäbchen mit abgerundeten Enden. Die Stichculturen waren bei Brüttemperatur nach 24 Stunden, ein Finger breit von der Oberfläche des Agar freilassend, bis zum Boden des Glases unter Gasbildung ziemlich gut gewachsen. Nach zwei Tagen wurden von einer Cultur Deckglaspräparate angefertigt und mikroskopisch

${ }^{1}$ Diese Zeitschrift. Bd. VI. S. 105-116. 
untersucht. Es warer dieselben Bacillen, welche auf Platten unter Wasserstoff sich entwickelt hatten; hier und da zeigten sich schon glänzende, ovale Körperchen (Sporen). Drei Meerschweinchen wurden mit dieser Cultur subcutan geimpft und starben nach 30 bis 40 Stunden sämmtlich an typischem Rauschbrand, d. h. unter Gasbildung im Unterhautbindegewebe; ausserdem waren Muskeln und Bindegewebe durchtränkt mit reichlicher, blutig-seröser Flüssigkeit, die Muskeln schwärzlich verfärht, die Lymphdrüsen stark hyperämisch; in der blutig-serösen Flüssigkeit und in den Muskeln fanden sich reichliche Mengen der oben genannten Bacillen. Zwei Meerschweinchen wurden dann mit Stückchen Fleisch von diesen Thieren weiter geimpft and gingen wieder unter denselben Erscheinungen zu Grunde.

Die Bacillen wurden in fortlatenden Culturen fortgezüchtet, ohne dabei ihre Virulenz zu verlieren. Hiernach bleibt es mir allerdings vorläufig noch unverständlich, warum es mir früher nicht gelungen war, den Rauschbrandbacillus in festen Nährböden zu züchten. Die in der angegebenen Weise erhaltenen Culturen wachsen sowohl in Gelatine wie in Agar, sowohl bei neutraler als auch bei schwach alkalischer Reaction.

\section{Verhalten der Cultaren.}

Wie schon erwähnt, sind die Rauschbrandbacillen obligat anaërobe Bacterien, und zwar sind sie unter den drei bisher bekannten pathogenen Arten, d. h. den Tetanus-, malignen Oedem- und Rauschbrandbacillen, die strengsten Anaëroben. Sie wachsen auf gewöhnlichen Platten gar nicht, wohl aber auf Platten im geschlossenen Raume unter Wasserstoff, nicht unter Kohlensäure. In Stichculturen beginnt das Wachsthum ein bis zwei Finger breit unter der Oberfläche der Nährgelatine bezw. -Agar.

Die Rauschbrandbacillen gedeihen schneller und kräftiger, wenn man zu gewöhnlichem Agar resp. Gelatine 1.5 bis 2 Procent Traubenzucker oder 4 bis 5 Procent Glycerin oder eine bestimmte Menge von stark reducirenden Substanzen, wie indigschwefelsaurem Natrium, ameisensaurem Natrium, Brenzkateehin, Hydrochinon, Resorcin, Eikonogen u. s. w. zusetzt, worüber an anderer Stelle von Hrn. Th. Weyl und mir gemeinschaftlich ausführlichere Mittheilungen gemacht worden sind. ${ }^{1}$

Die Rauschbrandbacillen behalten in festen Nährböden fortdauernd ihre Virulenz, was bei der Cultur in Meerschweinchenbouillon nicht der Fall war.

${ }^{1}$ Zux Kenntniss der Anaëroben. Dieses Heft. S. 41-\$7. 


\section{Aussehen der Colonieen.}

Die einzelnen Colonieen, in geschlossenen Gefässen ${ }^{1}$ in Gelatine unter Wasserstoff gewachsen, bilden zuerst unregelmässige Kugeln mit leicht warziger Oberfläche. Im nächsten Stadium verflüssigen sie die Umgebung, in welche die Fäden strahlenartig hineinwachsen, so dass bei durchfallendem Lichte ein dunkles Centrum mit unregelmässiger Oberfläche von einem Strahlenkranze umgeben erscheint (s. Fig. 1).

In der Sticheultur in hoher Schicht von Nährgelatine fangen die Rauschbrandbacillen an, bei Zimmertemperatur ron 20 bis $25^{\circ}$ nach zwei his drei Tagen ein bis zwei Finger breit unter der Oberfläche der Gelatine durch den Stichcanal nach unten hin zu wachsen, verflüssigen langsam die Gelatine unter Gasbildung und kommen bei den alten Culturen fast bis zur Oberfläche der Gelatine empor, so dass bei den Stichculturen der Rauschbrandbacillen nichts Charakteristisches zu bemerken ist (s. Fig. 2).

In der Agarstichcultur bei Brüttemperatur fangen sie nach 24 bis 48 Stunden einen Finger breit unter der Oberfläche unter Gasbildung an zu wachsen und liefern einen eigenthümlich säuerlichen, penetranten Geruch. Die Sporen bilden sich hier schon nach 30 Stunden.

\section{Temperaturverhältnisse.}

Die Rauschbrandbacillen gedeihen am besten bei Brüttemperatur von 36 bis $38^{\circ} \mathrm{C}$. Sie können aber auch bei Zimmertemperatur von 16 bis $18^{\circ}$ langsam wachsen; unter $14^{\circ}$ kommt kein Wachsthum mehr vor. Die Bacillen bilden in den Culturen bei Brüttemperatur rasch Sporen, während bei Zimmertemperatur die Sporenbildung erst später auftritt.

\section{Mikroskopische Untersuchung der Rauschbrandbacillen.}

Die Bacillen bleiben in der Gelatinecultur bei Zimmertemperatur meist einzeln als gerade Stäbchen mit abgerundeten Enden (s. Fig. 3). Im Brütapparate in der Agarcultur bilden sie rasch Sporen; die Sporen sind oval, an der einen Längsseite etwas abgeflacht, dicker als der Bacillenfaden und liegen nahezu in der Mitte des Baeillus, doch dem einen Ende desselben ein wenig genähert, so dass der Bacillus im sporenhaltigen Zustande spindelförmig aussieht (s. Fig. 4).

Beweglichkeit der Bacillen. Die Rauschbrandbacillen besitzen eine deutliche Eigenbewegung. Sporenhaltige Bacillen sind aber unbeweglich.

1 Die Beschreibung eines solchen Gefässes siehe diese Zeitschrift, Bd. VII; S. 227: Ueber den 'T'tanusbacillus. 
Färbungsverfahren. Die Rauschbrandbacillen färben sich mit den gebräuchlichen Anilinfarben gleich gut, dagegen nehmen ihre ovalen, echten Sporen die gewöhnlichen Farbstoffe nicht an. Die sporenhaltigen Bacillen lassen sich dann sehr gut doppelt färben, wenn man sie erst nach Ziehl und dann mit Methylenblaulösung behandelt; Gram'sche Doppelfärbung ist nicht anwendbar.

\section{Lebensdauer der Sporen.}

Sporenhaltige Culturen oder Fleisch, welche man an Seidenfäden angetrocknet und dann einige Tage lang im Exsiccator über Schwefelsäure, später an gewöhnlicher Luft aufbewahrt hat, sind mehrere Monate lang wirksam; ebenso lange Zeit bewahrt Rauschbrandfleisch seine Wirksamkeit, wenn es als dickes Stück getrocknet ist, eben weil sich Sporen darin bildeten, bevor es in seiner ganzen Dicke vollständig austrocknen konnte.

\section{Widerstandsfähigkeit der Sporen gegen Hitze und Chemikalien.}

Die Rauschbrandsporen sind gegen Hitze ziemlich widerstandsfähig; eine Stunde lang auf $80^{\circ}$ erhitzt, behalten sie noch ihre Virulenz, dagegen werden sie bei $100^{\circ}$ im Dampfapparate innerhalb fünf Minuten getödtet.

Fünfprocentige Carbolsäure tödtet die Sporen erst nach zehn Stunden, während die sporenfreien Bacillen binnen drei bis füṇ Minuten darin schon zu Grunde gehen; in einer einpromilligen Sublimatlösung werden die Sporen schon nach zwei Stunden vernichtet. Wenn man zu Carbol- bezw. Sublimatlösung Salzsäure zusetzt, so tritt die Wirkung viel schneller ein.

Bemerkt sei hier, was ich in meiner früheren Mittheilung bereits erwähnt habe, dass es mir fraglich zu sein scheine, ob die Rauschbrandbacillen schon im. lebenden Thierkörper Sporen bilden und ob die im Bacillus enthaltenen unregelmässigen, glänzenden Körperchen, welche hesser gefärbt werden können als der Bacillus selbst, wirklich Sporen bezw. Dauerformen seien. Jetzt hat es sich nun herausgestellt, dass diese leicht färbbaren, glänzenden Körperchẹn weder Sporen noch Dauerformen sind.

Die echten Rauschbrandsporen (Dauerformen) bilden sich erst dann im Thierkürper, wenn das Thier bereits gestorben ist und danach 24 bis 48 Stunden verlaufen sind. 
Wenn man die blutig-seröse Flüssigkeit oder den Muskelsaft eines Rauschbrandthieres entweder vor oder gleich nach dem Tode mikroskopisch untersucht, so findet man die auf gewöhnliche Weise nicht färbbaren, ovalen Körperchen im Bacillus nicht; wenn das Thier aber 24 bis 48 Stunden nach dem Tode untersucht wird, so sind schon in vielen Bacillen jene nach Ziehl färbbaren, ovalen Körperchen vorhanden.

Ich habe ferner theils gleich nach dem Tode des Thieres, theils 30 bis 48 Stunden später Seidenfäden mit Muskelsaft imprägnirt und. trocknen lassen. Nach einem Monate wurden je drei Meerschweinchen mit diesen beiden Arten von Seidenfäden geimpft; es starben diejenigen Neerschweinchen, welche mit den Seidenfäden behandelt waren, die 30 bis 48 Stunden nach dem Tode des eingegangenen Thieres imprägnirt worden waren, und zwar starben sie nach 48 Stunden am typischen Rauschbrand, während diejenigen, welche mit den gleich nach dem Tode präparirten Seidenfäden behandelt wurden, alle am Leben blieben. Die letzteren Seidenfäden erwiesen sich bei wiederholten Versuchen stets als unwirksam, während die ersteren nach mehreren Monaten noch immer ihre Virulenz behielten.

Ferner habe ich Stückchen Fleisch theils gleich nach dem Tode (sporenfrei), theils nach zwei Tagen (sporenhaltig) aus dem Cadaver eines an Rauschbrand gestorbenen Thieres in kleine Stückehen geschnitten, in Reagensgläser gethan, mit etwas Wasser gemischt und dann in's Wasserbad, welches vorher auf $65^{\circ} \mathrm{C}$. erwärmt war, 20 Minuten lang gebracht. Mit diesem Materiale wurden wiederum je drei Meerschweinchen geeimpft. Die Resultate waren genau ebenso wie bei den Seidenfäden, d. h. das gleich nach dem Tode erhitzte Fleisch war unwirksam, während das nach zwei Tagen präparirte Material die sämmtlichen Versuchsthiere durch Rauschbrand tödtete.

Hieraus kann man folgende Schlüsse ziehen:

1. Die im Rauschbrandbacillus enthaltenen, durch die gewöhnlichen Methoden leicht färbbaren, glänzenden, unregelmässigen Körperchen sind weder Sporen noch irgend welche Dauerformen, wie Metschnikoff angiebt.

2. Die Sporen der Rauschbrandbacillen bilden sieh erst dann im Thierkörper, wenn einige Zeit nach dem Tode des Thieres verstrichen ist; sie entstehen auch in festen $\mathrm{Nähr}$ böden oder in gekochten Kartoffelschichten. Die Form der Rauschbrandsporen ist stets oval.

3. Die Sporen lassen sich erst dann färben, wenn man sio nach Zjehl behandelt; dagegen können sie nach Gram nicht gefärbt werden. 
Ich glaube, diese Mittheilungen werden genügen, um das kritische Referat des Hrn. Metschnikoff ${ }^{1}$ über die Sporenbildung der Rauschbrandbacillen im lebenden Thierkörper, welches er meiner früheren Mittheilung gegenüber gegeben hat, richtig zu stellen.

\section{Thierversuche mit der Reincultur der Rauschbrandbacillen, welche in festen Nährböden gewachsen sind.}

Die Meerschweinchen, welche mit einem Stückchen Agarcultur von Rausehbrandbacillen subcutan geimpft werden, erkranken nach 20 Stunden regelmässig an Rauschbrand und gehen nach 30 bis 48 Stunden daran zu Grunde. Die pathologischen Erscheinungen sind ganz genau dieselben, wie ich sie schon oft erwähnt habe. Ferner verlieren die in festen Nährböden gewachsenen Culturen nach weiteren Generationen ihre Virulenz nicht.

Auf Wunsch des Hrn. Metschnikoff ${ }^{2}$ erwähne ich diesmal den Versuch von Roux; ${ }^{3}$ nach ihm sollen diejenigen Meerschweinchen, welche gegen den Rauschbrand immun gemacht worden waren, auch gegen das maligne Oedem geschützt sein. Ich bedaure, dass meine wiederholten Versuche mit den Resultaten des Hrn. Roux nicht übereinstimmen. Es wurden nämlich im Ganzen zwanzig Meerschweinchen mit abgeschwächten, unwirksamen Rauschbrandculturen behandelt, sie überstanden die Impfung; nach zwei Wochen wurden die sämmtlichen Meerschweinchen wiederum mit virulenten Rauschbrandculturen geimpft, keines derselben ist an Rauschbrand gestorben, d. h. alle blieken am Leben, während drei zur Controle mit denselben virulenten Culturen geimpfte Ireerschweinchen sämmtlich am typischen Rauschbrand starben; nun wurden diese gegen Rauschbrand immunisirten Meerschweinchen nach ein bis zwei Wochen mit den Culturen der malignen Oedembacillen behandelt und gingen nach 24 bis 40 Stunden ausnahmslos an Oedem zu Grunde. Die Meerschweinchen, welche also für Rauschbrand refractär waren, starben an malignem Oedem ebenso gut, wie die Meerschweinchen, welche gegen den Rauschbrand nicht immunisirt worden waren.

${ }^{2}$ Annales de l'institut Pasteur. 1889. Nr. 6.

2 A. a. $O$.

${ }^{3}$ E. Roux, Immunité contre le charbon symptomatique conférée pár les suh. stances solubles. Annales de l'institut Pasteur. 1888. Nr. 2. 
Die Abbildungen hat Hr. Prof. Dr. Doenitz gezeichnet, wofür ich ihm meinen besten Dank hier ausspreche; ferner habe ich Hrn. Prof. Dr. Kitt in München für die liebenswürdige Ueberlassung des Fleisches von an Rauschbrand gestorbenen Rindvieh besteus zu danken.

\section{Erklärung der Abbildungen.}

(Tafel III.)

Fig. 1. Colonie der Rauschbrandbacillen in Nährgelatine; 8 Tage alt, bei Zimmertemperatur von $18-20^{\circ} \mathrm{C}$.

Fig. 2. Stichcultur der Rauschbrandbacillen in Nährgelatine; 10 Tage alt, bei Zimmertemperatur von $18-20^{\circ} \mathrm{C}$.

Fig. 3. Rauschbrandbacillen aus einer Gelatinecultur; sporentreie Stäbchen.

Fig. 4. Rauschbrandbacillen aus einer Agarcultur; sporentragende Stäbchen.

\section{Berichtigung.}

Durch einen bösen Zufall ist gerade der wichtigste Theił meiner Arbeit: „Die negative Indolreaction der Typhusbacillen im Gegensatz zu anderen ähnlichen Bacillenarten" (diese Zeitschrift, Bd. VII, S. 515-520) durch einige Druckfehler arg entstellt. Ich bringe denselben deshalb corrigirt hier nochmals zum Abdruck:

Das Verfahren ist folgendes ( $\mathrm{S} .518$ );

Man setzt $z$ u $10^{\mathrm{cm}}$ peptonhaltiger alkalischer Bouilloneultur der zu untersuchenden Bacterien, welche 24 Stunden lang bei Brüttemperaturgestanden hat, 1 cem einer Lösung von reinem Kaliumnitrit, die 0.02 in $100^{\mathrm{cem}}$ enthält und dann einige Tropfen coucentrirter Schwefelsäure $z u$, so tritt bei Gegenwart des Indols rosa- oder tiefrothe Färbung ein.

An den beiden übrigen Stellen (S. 518, Zeile 19 v. o. und S.519, Zeile 7 v. o.) ist die entsprechende Verbesserung anzubringen. 
Fig. 1.

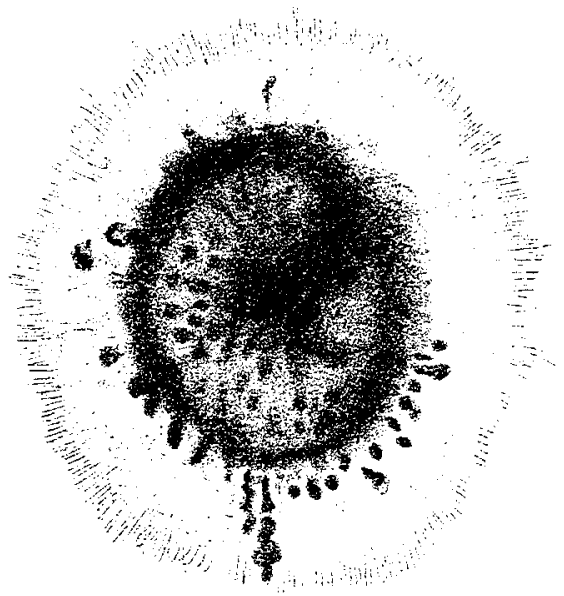

Py?

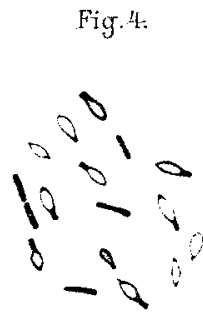

Fig. 3.
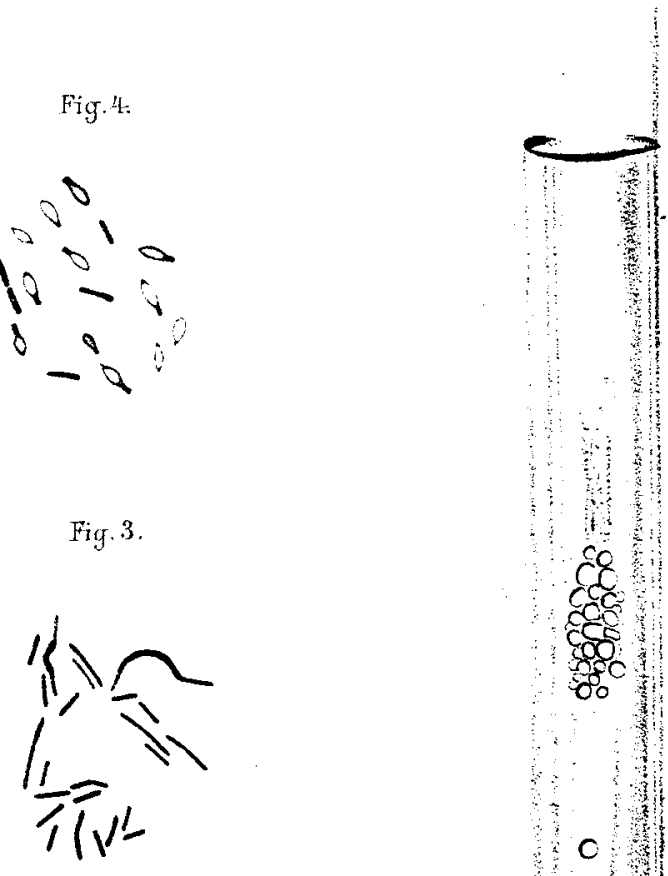